\title{
Correction to: Complementary and Alternative Medicine Among Persons living with HIV in the Era of Combined Antiretroviral Treatment
}

\author{
Sean N. Halpin ${ }^{1}$ - Edwin Clayton Carruth ${ }^{2} \cdot$ Ramona P. Rai $^{2} \cdot$ E. Jennifer Edelman ${ }^{3}$. \\ David A. Fiellin ${ }^{3}$. Cynthia Gibert ${ }^{4}$ - Kirsha S. Gordon ${ }^{4}$. Wei Huang ${ }^{2}$. \\ Amy Justice ${ }^{4}$. Vincent C. Marconi ${ }^{5}$. David Rimland ${ }^{5}$. Molly M. Perkins ${ }^{5}$
}

Published online: 9 March 2018

๑) Springer Science+Business Media, LLC, part of Springer Nature 2018

\section{Correction to: AIDS Behav (2018) 22:848-852 \\ https://doi.org/10.1007/s10461-017-1866-7}

In the original publication of the article, the given and family name of the fourth author was not correct. The name has been corrected with this erratum.

The original article can be found online at https://doi.org/10.1007/ s10461-017-1866-7.

Sean N. Halpin

sean.nathaniel.halpin@emory.edu

Edwin Clayton Carruth

ccarruth42@gmail.com

Ramona P. Rai

Ramona.Rai@va.gov

E. Jennifer Edelman

eva.edelman@yale.edu

David A. Fiellin

david.fiellin@yale.edu

Cynthia Gibert

Cynthia.Gibert@va.gov

Kirsha S. Gordon

Kirsha.Gordon2@va.gov

Wei Huang

Wei.Huang@va.gov

Amy Justice amy.justice2@va.gov

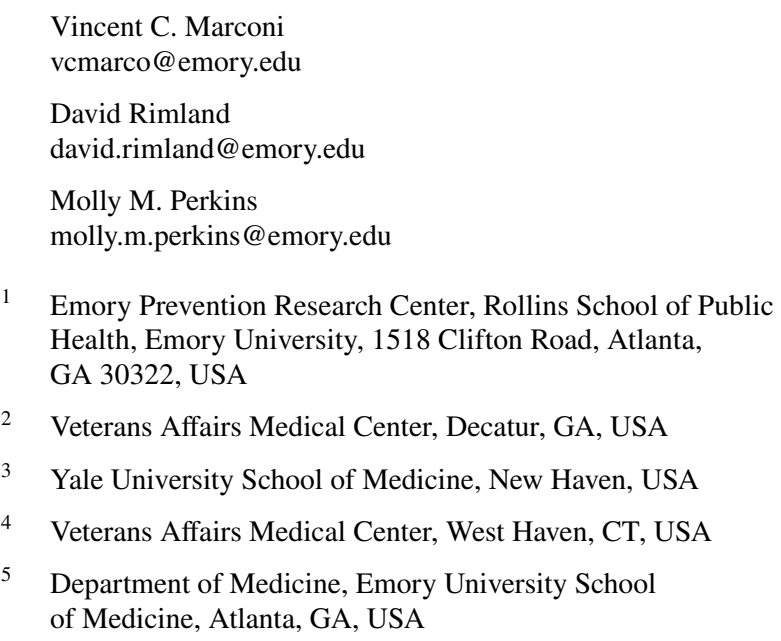

